factor VIII-Von Willebrand complex is reviewed in the next section. Three chapters are devoted to fibrinolysis and fibrinogen followed by three on diagnosis and management. The final chapter is on distribution of levels of coagulation factors in large population groups.

The contributors are all authorities in their own fields. This number must be available to all those working in coagulation and to all those who wish to acquire a deeper understanding of recent developments in this very complex arena.

\section{Haemostatic Drugs. A Critical Appraisal}

By M. Verstraete. Pp. $x+155$, hard cover. The Hague: Martinus Nijhoff BV Publishers, 1977. Dfl. 45 (exclusive of Dutch tax).

This book lists some 20 compounds which are alleged to influence haemostasis and which are or were marketed by various pharmaceutical companies. Most have been given to patients (or volunteers) but few appear to have undergone the type of tests mandatory in the U.K. Some indeed have been withdrawn from the market. None appears to have shown unequivocal benefit in a clinical situation.

To quote one manufacturer '.... since its introduction, substance $X$ has been administered in millions of cases . . . clinical trials .... on the clinical efficacy are underway'.

It is difficult to see what purpose is served by bringing together these accounts of materials under investigation by drug companies. Some, such as epsilon aminocaproic acid, trasylol and tranexamic acid, have some role as fibrinolytic agents. The rest, however, would appear to be several years away from clinical application and probably unlikely to reach that state.

\section{Scanning Electron Microscopy 1976}

(Vols 1 and 2)

Conference proceedings, edited by OM JCHARI and ROBERT

P. BeCKer. Sponsored by IIT Research Institute, Chicago, Illinois 60616. Pp. 782 and 708, illustrated. \$57.50.

These two volumes constitute the ninth in a series of conference proceedings which have appeared annually since 1968 (there are also two volumes stemming from the 1977 Conference). The papers which make up these books were published at the time of the conference and are full reports of the material presented verbally, as distinct from the abstracts common in much of the publishing related to conferences. In fact, they constitute an annual journal of scanning electron microscopy, emanating mostly from North America, with fewer contributions from the United Kingdom, Japan and other European and English speaking countries.

The contents of Volume I mostly relate to physical aspects of the techniques of scanning electron microscopy and its applications in materials sciences; Volume II contains chiefly biological and medical applications reports. A great many of the papers in both volumes will be of interest to medical scientists who are seriously concerned to use the SEM in their own studies, and these volumes can only be considered very good value for money by today's standards. They constitute a unique source of reference to the existing literature on scanning electron microscopy as well as providing up-to-date information in themselves. A particularly useful feature in this regard is the bibliography of biological and medical applications covering, for the most part, the years 1974 and 1975, which updates the earlier bibliographies to be found in the 1973 and 1974 volumes. These applications bibliographies are fully indexed according to subject matter.
Shaw's Textbook of Operative Gynaecology

(4th edition). Revised by JOHN Howkins and CHRISTOPHER N. Hudson. Pp. 547, hard cover, illustrated. Edinburgh: Churchill Livingstone, 1977. £35.00.

When taking over editing of another author's book, there is, inevitably, a tendency to preserve much of the original for reasons of sentimentality and respect.

Happily, over succeeding editions, John Howkins has been able to preserve the original intent to have a text book of gynaecological surgery with emphasis on accepted British practice.

New material has been introduced and existing chapters revised extensively with succeeding editions and in this, the fourth edition, he has been assisted by Christopher Hudson. Included now are sections on diagnostic radiology, gynaecological endoscopy and chemotherapy in gynaecological malignant disease; other sections have been extensively revised.

It is invidious to single out any particular chapter but mention must be made of the excellent section on treatment of bladder and ureteric injuries and the management of urinary fistulae.

A model of clarity, profusely illustrated, this is a book to grace the shelf of every practising gynaecological surgeon. However, as a sign of the times, the price is high (and is five times as expensive as the previous edition nine years ago) which may mean that for many junior postgraduates it will have to be borrowed from the library shelf.

\section{Shock}

By I. Şuteu, T. Băndila, A. Cafrită, A. I. Bucur and V. CANDEA. Pp. xxi +447 , hard cover, illustrated. Tunbridge Wells: Abacus Press, 1977. £18.95.

This book was originally published in Rumania in 1973. It embodies the results, conclusions as well as many general review sections into the difficult problem of the shock state. All the authors have been working as a team under the guidance of the Professor of Surgery at the Bucharest University School of Medicine. The book is the epitome of an extensive ten-year programme of experimental, haemodynamic, isotopic, enzymatic, histological and electron microscopic evaluation of the subject of shock.

Whilst admiring this team for undertaking research into an unstable clinical state, and correspondingly a very difficult subject to study, this monograph has certain limitations to the reader outside Eastern Europe.

Firstly, since it was originally published in 1973, there are no recent references. Also many of the references of publications in Eastern Europe are difficult for the outside reader to find or evaluate. The selected Bibliography which occurs at the end of each chapter is limited in its scope and outdated. The authors deal with experimental shock and describe in detail many of their own experiments. This part of the book appears as a distillate of their own original experimental papers and suffers in that it does not approach this problem in a review nature. In describing their experiments into shock, multiple electron-microscopic figures of the liver of a dog in shock are presented, which is disproportionate to the amount of information covered in the rest of the book.

In reviewing, the essential nature of shock in the neurological and endocrinological system, the authors often equate the comatosed state with the shock situation, somewhat stretching the definition of the subject.

Whilst dealing with the metabolism of shock, little information is given on new experimental results of the metabolic changes produced by the shock state. Instead, a rather weak general review of cellular metabolism is described. In other aspects of this book, particularly when dealing with 
the electro-physiology of the cell and also of the neurohormonal system of the body, a very weak general review is presented and no new information.

On many occasions throughout the book, the syntax utilized is confusing to the non-Eastern European reader, for example the use of the word haemodynamosat which appears to refer to the circulation. A further general example of the confusing nature of the literary style of this book can be seen on page 99. 'Congruous synchronisation of all the links of the systemic response may sometimes re-establish the situation starting from a postaggressive (postinjury) oscillating systemic reaction'.

To the pedant, numerous spelling errors also occur in this book. Furthermore, many of the pharmacological agents used in the experiments in this monograph, have names unfamiliar to the non-Eastern European reader.

In recent years the use of the Swan-Ganz balloon-directed catheter has enabled the critically ill shocked patient to be monitored. Also after-load-reducing agents such as nitroprusside, phentolamine and nitroglycerin are widely used in clinical practice in the treatment of cardiogenic shock as is the balloon counter pulsation device. There is no mention of any of these newer approaches to the shock state in this monograph.

In conclusion, this book cannot be widely recommended as an advance into the understanding or experimental evalua tion of the shock state. It suffers from too brief and basic reviews of the general organ systems which are sometimes unrelated to the shocked state. Also the syntax and literary style are confusing to the reader on many occasions and the very fact that it was first published in 1973 renders it considerably out of date in our current knowledge and thinking of the condition of shock.

At a price of $£ 18.95$ it cannot be widely recommended.

\title{
Notice
}

\author{
International Society and Federation of Cardiology \\ Scientific Council on Cardiomyopathies
}

A ONE DAY SYMPOSIUM ON

\author{
CA R D I O M Y O PAT H Y \\ Cause, Course and Cure
}

will be held at

\section{THE MEETING ROOMS OF THE ZOOLOGICAL SOCIETY OF LONDON REGENT'S PARK}

on

THURSDAY, 12TH JANUARY, 1978

Speakers will include: W. Abelmann (USA), D. Amorim (Brazil), W. Beck (S. Africa), H.-D. Bolte (W. Germany), J. F. Goodwin (UK), H. Kuhn (W. Germany), C. M. Oakley (UK), E. G. J. Olsen (UK), R. Pridie (UK), A. Torp (Sweden), A. P. Waterson (UK).

Further information may be obtained from: Dr E. G. J. Olsen, Chairman of the Scientific Council on Cardiomyopathies, International Society and Federation of Cardiology, National Heart Hospital, Westmoreland Street, London W1M 8BA. 